\title{
Diverse Roles and Therapeutic Potentials of Circular RNAs in Urological Cancers
}

\author{
Song Wang, Yufan Ying, Xueyou Ma, Weiyu Wang, Xiao Wang * and Liping Xie* \\ Department of Urology, The First Affiliated Hospital, School of Medicine, Zhejiang University, Hangzhou, China
}

\section{OPEN ACCESS}

Edited by:

Amaresh Chandra Panda,

Institute of Life Sciences (ILS), India

Reviewed by:

Piyush Khandelia,

Birla Institute of Technology and

Science, India

Nirmal Parajuli,

Henry Ford Health System,

United States

*Correspondence:

Xiao Wang

zjuwangxiao@zju.edu.cn

Liping Xie

xielp@zju.edu.cn

Specialty section:

This article was submitted to

Protein and RNA Networks,

a section of the journal

Frontiers in Molecular Biosciences

Received: 20 August 2021

Accepted: 20 October 2021

Published: 19 November 2021

Citation:

Wang S, Ying $Y$, Ma $X$, Wang W, Wang $X$ and $X i e L$ (2021) Diverse Roles and Therapeutic Potentials of Circular

RNAs in Urological Cancers.

Front. Mol. Biosci. 8:761698.

doi: 10.3389/fmolb.2021.761698
Circular RNAs (circRNAs) are a novel class of noncoding RNAs, which are mainly formed as a loop structure at the exons caused by noncanonical splicing; they are much more stable than linear transcripts; recent reports have suggested that the dysregulation of circRNAs is associated with the occurrence and development of diseases, especially various human malignancies. Emerging evidence demonstrated that a large number of circRNAs play a vital role in a series of biological processes such as tumor cell proliferation, migration, drug resistance, and immune escape. Additionally, circRNAs were also reported to be potential prognostic and diagnostic biomarkers in cancers. In this work, we systematically summarize the biogenesis and characteristics of circRNAs, paying special attention to potential mechanisms and clinical applications of circRNAs in urological cancers, which may help develop potential therapy targets for urological cancers in the future.

Keywords: circular RNAs, urological cancers, biomarker, therapy targets, mechanism

\section{INTRODUCTION}

Recently, plentiful researches have delineated sophisticated regulatory networks formed by diverse RNA species, including protein-coding messenger RNAs (mRNAs) and noncoding RNAs represented by circular RNAs (circRNAs) and microRNAs (Tay et al., 2011; Luigi et al., 2018; Xu et al., 2019; Zhao Q. et al., 2020; Vitiello et al., 2020). Emerging evidence showed that noncoding RNAs make up the majority of the total transcriptome, whereas only $2 \%$ of the human transcriptome are protein-coding mRNAs (Boley et al., 2014). With a deeper understanding of the transcriptional landscape, the noncoding RNAs have shown their significances in the pathogenesis of diverse human diseases, especially in cancers (Slack and Chinnaiyan, 2019). We previously elucidated that microRNAs (miRNAs) are involved in the occurrence and development of urological cancers such as renal cell carcinoma (RCC), bladder cancer (BC), and prostate cancer (PCa) (Li J. et al., 2017; Wang S. et al., 2017; Zhu et al., 2020), whereas the circRNAs in urological tumors remain poorly understood.

As rising stars in noncoding RNAs, circRNAs have attracted more and more attention from researchers all over the world. However, they were traditionally considered as nonfunctional "genomic junks" generated by abnormal splicing events and until specific-expressed circRNA in

Abbreviations: AR, androgen receptor; AUC, area under the curve; BC, Bladder cancer; ceRNAs, competing endogenous RNAs; ciRNAs, circular intronic RNAs; CRPC, castration-resistant prostate cancer; ElciRNAs, exon-intron circRNAs; FN1, fibronectin 1; MREs, miRNA response elements; PCa, Prostate cancer; RCC, Renal cell carcinoma. 


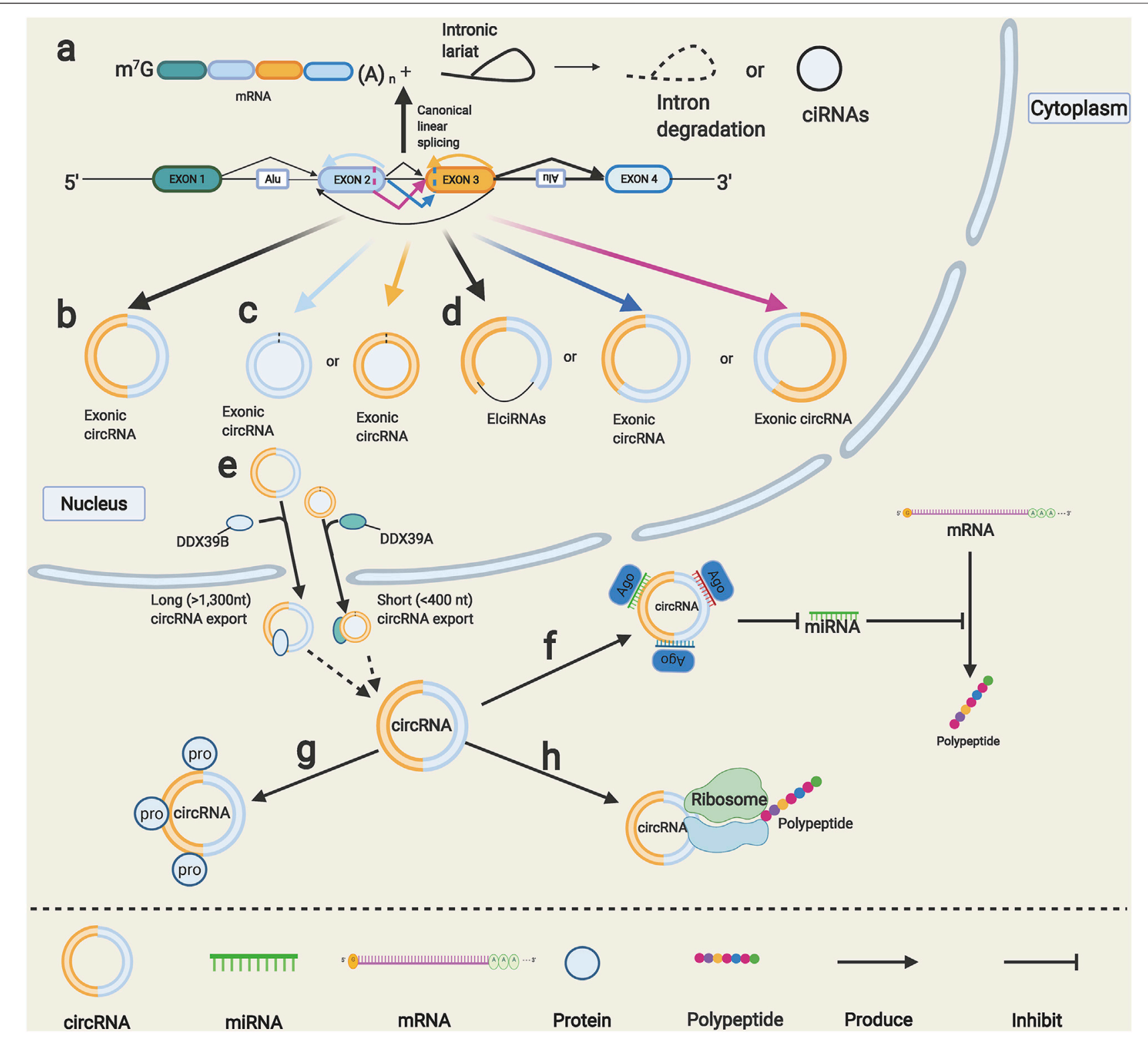

FIGURE 1 | Formation and functions of circRNAs. (A) Canonical linear splicing can produce normal linear mRNA (left) and intronic lariat (right), intronic lariat rapidly degraded after splicing or escape from debranching step then generate circular intronic RNAs (ciRNAs) (right). (B) Back-splicing of exons produces circRNAs. (C) Alternative back-splice yields different single-exon circRNAs. (D) Alternative splice that happened within circRNAs produces three basic types of circRNAs. (E) Output of circRNAs from nucleus to cytoplasm requires unique proteins mediation. (F) CircRNAs can function as miRNA sponge to indirectly regulate miRNA downstream target genes. (G) CircRNAs can directly interact with proteins to regulate their functions. (H) CircRNAs can translate unique peptides.

testicular tissue was found to have potential functions (Capel et al., 1993; Wilusz and Sharp, 2013). Recently, novel analysis such as the RNase R-treated and non-polyadenylated transcriptomes analysis have determined thousands of circRNAs in a great diversity of eukaryotes, including humans (Jeck et al., 2013; Vicens and Westhof, 2014; Zhang et al., 2014), and discovered them to have species-specific, tissue-specific, and time-specific expression patterns (Chen, 2016). Meanwhile, plentiful researches elucidated that the circRNAs are extensively involved in cancer cell growth and innate immunity, and their dysregulation is closely correlated with disease occurrence and progression (Dube et al., 2019; Huang et al., 2019; Vo et al., 2019; Wilusz, 2019), especially the initiation and development of human cancers (Guarnerio et al., 2019; Rajappa et al., 2020), including urological cancers (Chen S. et al., 2019; Lu et al., 2019; Li J. et al., 2020).

CircRNAs are mainly derived from nonconventional backsplicing, where the downstream site is ligated to the forward acceptor site (Vicens and Westhof, 2014). Remarkably, circRNAs were reported to express independently of homologous linear isoforms, and they can accumulate to high expression levels due to their complete closed-loop fabric, which endows them more 
tolerant to deterioration by exonucleases. It has been proposed that naturally expressed circRNAs not only can serve as endogenous miRNA sponges, or competing endogenous RNAs (ceRNAs), but also can act as protein antagonists or translation templates to regulate physiological and pathological activities (Chen, 2020). Understanding this novel regulatory network may yield insights into intricate gene regulatory systems in human development and disease progression. In our comprehensive work, we summarized the latest findings of circRNAs in biogenesis and characteristics, with a focus on their potential mechanisms and clinical applications in urological cancers, which may help us to develop potential therapy targets for urological cancers in the future.

\section{CIRCULAR RNAS}

\section{Origination, Classification, and Regulation of Circular RNAs}

Most eukaryotic genes contain one or more introns among multiple exons, and canonical linear splicing mechanisms usually remove the introns and ligate the exons together to yield mature mRNAs (Figure 1A). Although the competitions between linear splicing and noncanonical splicing have always existed in human transcriptome, as the conventional linear splicing events slow down, the circular RNAs will be produced by an alternative nonconventional splicing event called backsplicing, in which a backward donor site is covalently linked to a forward acceptor site (Tay et al., 2014) (Figure 1B). Simultaneously, intron lariats resected during canonical splicing can escape debranching and retain the circular form in a few cases, which are dubbed as circular intronic RNAs (ciRNAs) (Zhang et al., 2013) (Figure 1A). Notably, although the odds are slight, a given gene locus that includes multiple exons can yield diverse circRNAs by a special form of back-splicing called alternative back-splicing (Gao et al., 2016); through this mechanism, each exon splices and combines its own set of $5^{\prime}$ donors and $3^{\prime}$ acceptors, thus producing circRNAs with backsplice sites from a single exon (Figure 1C). In addition, splicing sites within the circRNAs will also generate three novel circRNAs, including intron retention, alternative $5^{\prime}$ and $3^{\prime}$ splicing circRNAs, unlike conventional back-splicing (Zhang et al., 2016) (Figure 1D). When it comes to the classification of circRNAs, we generally focus on the components of them, and the circRNAs can be easily divided into three types: 1) exonic circRNAs, they are mainly generated in the nucleus and then exported to the cytoplasm; they can function as sponges for diverse miRNAs and proteins (Chen et al., 2015). 2) ciRNAs, are almost nonfunctional and distributed in the nucleus ( $\mathrm{Li} \mathrm{X}$. et al., 2021). 3) exon-intron circRNAs (ElciRNAs), found to interact with small nuclear ribonucleoproteins and bind to RNA polymerase II to regulate gene transcription ( $\mathrm{Li} \mathrm{Z}$. et al., 2015). Although the nucleus is the back-splicing events factory, most functional circRNAs are distributed in the cytoplasm. Recently, some researchers have proposed that the abundance of circRNAs was determined by the steady-state regulatory system composed of circRNA generation, nuclear export, and degradation (Conn et al., 2015; Chen, 2020). On the one hand, intronic complementary sequences have been proved to facilitate the generation of circRNAs (Zhang et al., 2014), and many RNA-binding proteins can regulate the production of circRNAs through binding to intronic complementary sequences. These include positive regulatory protein QKI, HNRNPL, and negative regulatory protein DHX9, ADAR1 (Conn et al., 2015; Rybak-Wolf et al., 2015; Aktaş et al., 2017; Fei et al., 2017). On the other hand, the circRNA nuclear export mechanisms remained unclear until a novel published study reported that circRNAs could transport from the nucleus to the cytoplasm depending on their length (Huang et al., 2018) (Figure 1E). CircRNAs can stably exist thus amass high expression levels because of their loop structures, which help them be tolerant to exonucleases leaded RNA degradation; several studies showed that the miRNA endonucleases might also be involved in circRNA degradation mechanisms (Hansen et al., 2011; Park et al., 2019).

\section{Biological Properties of Circular RNAs}

CircRNAs possess some unique biological characteristics that are different from other RNA: 1) circRNAs show a wide variety of diversity, more than a million circRNAs have been reported in the circAtlas database (Wu et al., 2020), and over a million cancerspecific circRNAs in the CSCD2 database (Feng et al., 2021). 2) High stability, circRNAs possess a longer half-life in comparison with linear RNA due to their loop structure (Enuka et al., 2016). 3) Highly conserved, a recent study showed that the sequences of some circRNAs were highly conserved among multiple species (Jeck et al., 2013). 4) Expression specificity, different tissues were reported to have a variable abundance of circRNAs (Salzman et al., 2013). For example, cirs-7 was detected as highly expressed in neural tissues while decreased in other tissues (Memczak et al., 2013).

\section{Functions of Circular RNAs}

CircRNAs can serve as miRNA sponges. As early as 2007, researchers found an intriguing phenomenon called "target mimicry," in which a noncoding RNA can sequester miR-399 and release its downstream targets (Franco-Zorrilla et al., 2007). In 2011, Leonardo et al. unified the hypothesis about how gene coding mRNAs and noncoding RNAs coregulate and affect each other by using MREs as "communication media." In that research, the term "competing endogenous RNA" (ceRNA) was coined to describe this new layer of a regulatory network across the transcriptome (Salmena et al., 2011). Henceforth, more and more circRNAs were identified to function as ceRNAs, also known as miRNA sponges that bind corresponding target miRNAs and indirectly regulate the miRNAs target genes (Figure 1F). CircRNAs can also directly interact with proteins to cause their degradation or enhance their functions (Wang X. et al., 2021) (Figure 1G). In addition, some circRNAs were reported to have internal ribosome entry site elements and can be the templates for translation (Gao X. et al., 2021; Jiang T. et al., 2021; Wu et al., 2021) (Figure 1H). CircRNAs have been widely reported to be involved in regulating transcription factor activity, cell proliferation, epithelial-to-mesenchymal transition (EMT), 
and stem cells through targeting specific signaling pathways and genes. Chen et al. (2021) demonstrated that cia-MAF drives liver tumor progression via transcription factor MAFF; CircZFR was found to promote $\mathrm{BC}$ cell proliferation by targeting transcription factor ZEB2 (Zhang W.-Y. et al., 2019). CircPTCH1 and circCSNK1G3 were reported to promote the EMT process in RCC (Liu H. et al., 2020; Li W. et al., 2021). CDRlas and hsa_circ_0003222 were found to regulate stemness and development of lung cancer (Zhao Y. et al., 2020) (Li C. et al., 2021). Additionally, a novel circular RNA, named circSETD3, was reported to inhibit stem cell properties, cell growth, and EMT in BC (Tian et al., 2021). These studies showed that circRNAs are implicated in regulating cell proliferation, EMT, and stem cell properties by multiple mechanisms.

\section{Circular RNAs and Exosomes}

Exosomes are a kind of vesicles that are generated and secreted by almost all cell types; they are packed with a series of materials, including circRNAs, and act on the recipient cells, thus exerting biological functions (Zhang Y. et al., 2019). Emerging evidence demonstrated that exosome-derived circRNAs play vital roles in the progression of cancer (Reese and Dhayat, 2021). Gao L. et al. (2021) reported that the exosome-derived circCOG2 drives colorectal cancer progression by activating transforming growth factor-beta (TGF- $\beta$ ) signaling. Zang et al. (2021) found that exosomes that transferred circ_0000337 lead to cisplatin resistance of esophageal cancer. Exosome circ_0044516 was reported to drive PCa progression by targeting miR-29a-3p (Li T. et al., 2020). In contrast, Jiang Z. et al. (2021) reported that exosomal circEPB41L2 could inhibit colorectal cancer development by regulating the PTEN/AKT pathway. Several recent studies have shown that exosomes contain highly elevated expression of circRNAs due to their high protective properties, making exo-circRNAs promising biomarkers and targets for therapy (Li Y. et al., 2015; Shi et al., 2020).

\section{ROLES OF CIRCULAR RNAS IN HUMAN UROLOGICAL CANCERS}

Dysregulation of circular RNAs was reported to be implicated in the occurrence and development of urological cancers (Chen S. et al., 2019; Lu et al., 2019; Li J. et al., 2020); they were found to have extensively participated in the growth, apoptosis, invasion, and migration of urological cancers.

\section{Renal Cell Carcinoma}

RCC is one of the most common malignant tumors of the urinary system, accounts for $5 \%$ of male adult malignant tumors and $3 \%$ of female adult malignant tumors around the world (Siegel et al., 2020). Recently, some circRNAs have been reported to regulate RCC through affecting $\mathrm{PI} 3 \mathrm{~K} / \mathrm{AKT} / \mathrm{mTOR}$ signaling, which is involved in tumor proliferation, migration, and apoptosis, including activator circHIPK3 and inhibitor hsa-circ-0072309 (Chen T. et al., 2019). Circ-ZNF609 was reported to act as a competitive miR-138-5p sponge and suppress its expression, then release FOXP4 and promote the progression of RCC (Xiong et al.,
2019), whereas cRAPGEF5, derived from the RAPGEF5 gene, was downregulated in RCC and the sponged miR-27a-3p released, resulting in decreased expression of TXNIP and blocking the progression and migration of RCC (Chen Q. et al., 2020). Notably, microarray analysis identified that the upregulation of circRNA hsa_circ_001895 (Chen Z. et al., 2020) and circPCNXL2 (Zhou et al., 2018) could, respectively, sponge the miR-296-5p and miR-153, led to the liberty of transcription factor SOX12, ZEB2, and thus promote RCC proliferation.

Invasion and migration are particularly important characteristics in the occurrence and progression of malignant tumors; our previous research has reported that miRNA could affect the invasion and migration of RCC (Zhu et al., 2020); as the upstream regulatory molecule of miRNA, circRNAs have been observed to participate in the process of EMT and metastasis of RCC. Xue et al. (2019) reported that the lowly expressed circAKT3 in RCC leads to the freedom of its adsorbed miR-296-3p, which results in the reduction of EMT negative marker's expression and significantly increase the RCC tumor EMT process. However, highly expressed circ_000926 promotes the EMT process by boosting the expression of N-cadherin (Zhang D. et al., 2019). Studies have shown that the weak adsorption capacity of circHIAT1 causes the elevated expression of miR195-5p/miR-29a-3p/mi-R29c-3p, which indirectly leads to decreased CDC42 expression and inhibits the invasion and migration of RCC (Wang K. et al., 2017). Intriguingly, Han et al. (2018) found that circATP2B1 can stabilize miR-204-3p, which is not in accord with the conventional ceRNA theory; they reported that highly expressed ER $\beta$ suppress the expression of circATP2B1 and then led to the reduction of miR-204-3p, which caused the increased expression of EMT positively related marker FN1 and thus promoted RCC cell invasion (Figure 2).

\section{Bladder Cancer}

$\mathrm{BC}$ is a malignant tumor that is particularly prone to recurrence, which ranked the top 10 cancers all over the world, with extremely high mortality and morbidity (Barone et al., 2015). However, studies on early diagnosis of $\mathrm{BC}$ and specific markers are still lacking, and current treatments for $\mathrm{BC}$ are also unsatisfactory; it is important to further explore precise strategies for gene regulatory networks in BC. As a rising star in cancer, circRNAs also play pivotal roles in the progression of BC. CircTFRC was reported to be significantly upregulated in 57 cases of BC tissues compared with adjacent normal tissues, and with the increase of tumor stages and grades, its expression level enhanced significantly; miR-107 was proved to be sponged by highly expressed circTFRC, which led to the downstream target gene TFRC release and drive the progression of $\mathrm{BC}$, coincidentally; the target gene TFRC was the ancestral gene of circTFRC (Su et al., 2019). PI3K/AKT signaling pathway is a common and important transduction pathway for diversified cancer cell proliferation and metastasis (Zhang et al., 2017). Yang C. et al. (2019) applied RNA interference technology to silence the expression of circUVRAG. Downregulation of circUVRAG led to the upregulation of miRNA-223 and suppression of fibroblast growth factor receptor 2, which is an important activator of the PI3K/AKT signaling pathway. 


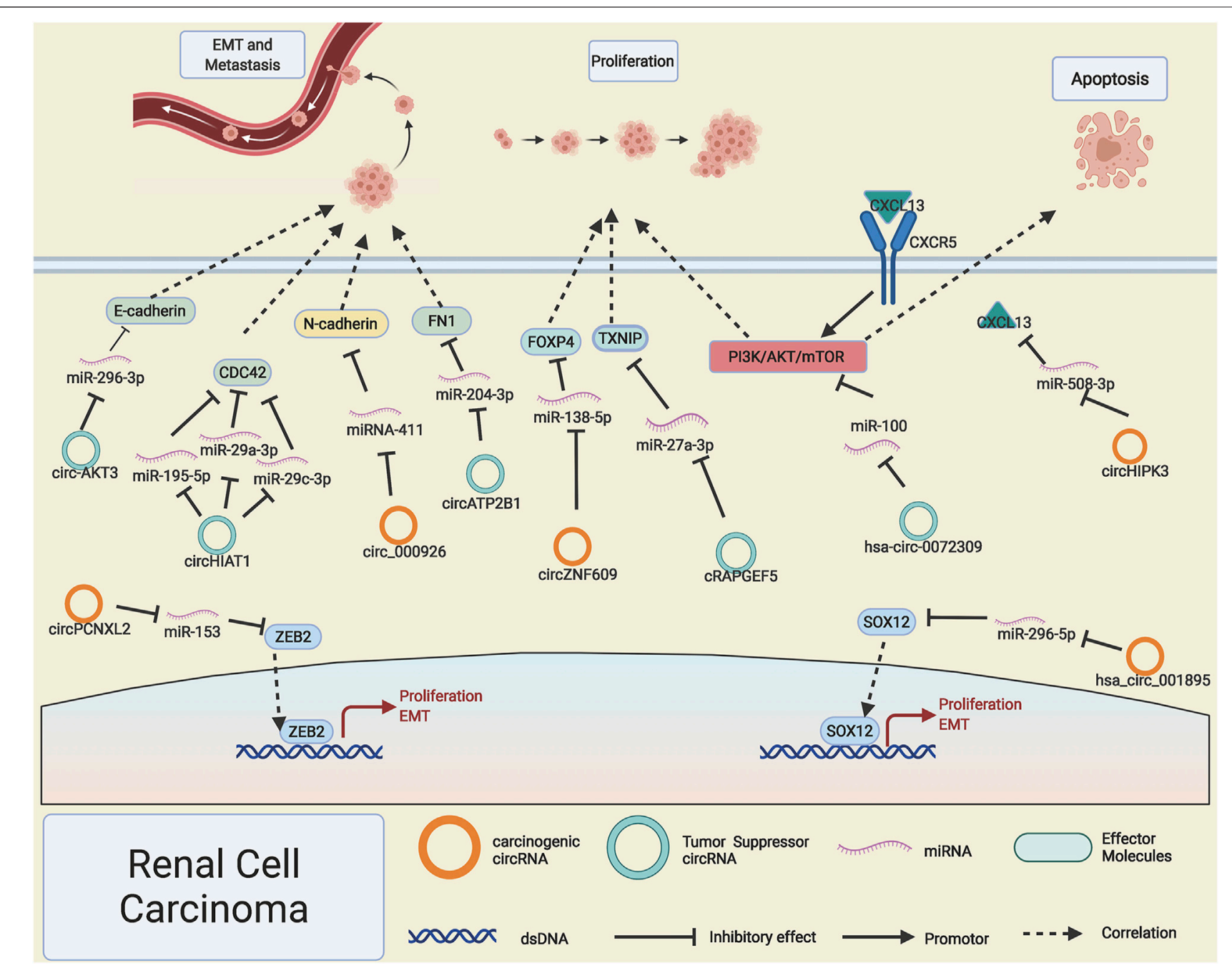

FIGURE 2 | Possible mechanisms of circRNAs in renal cell carcinoma. Upregulated circPCNXL2, circZNF609, hsa_circ_001895, circ_000926, and circHIPK3 (orange rings) and downregulated hsa-circ-0072309, cRAPGEF5, circ-AKT3, circATP2B1, and circHIAT1 (cyan rings) regulate progression of renal cell carcinoma by altering specific gene expression or tumor-related signaling pathways.

CircRNA circSLC8A1 was confirmed to be lowly expressed in nearly 100 pairs of BC tissues compared with adjacent normal tissues, which led to the discharge of downstream sponged miR494, miR-130b, and the depression of PTEN. PTEN has been widely considered as a tumor suppressor gene and negatively regulates the PI3K/AKT pathway (Lu et al., 2019).

EMT and angiogenesis processes are important hallmarks of BC progression (Yang et al., 2020). CircPRMT5 can drive the EMT process of $\mathrm{BC}$ by sponging miR-30c and liberating the transcription factor snail (Chen X. et al., 2018). CircHIPK3 contains two key miR-558 response elements due to its expression level being too low to sponge enough miR-558, resulting in lowly expressed HPSE inhibiting invasion and migration of BC cells ( $\mathrm{Li} \mathrm{Y}$. et al., 2017). Interestingly, circHIPK3 has been reported to play a role in driving tumor progression both in PCa and RCC (Liu F. et al., 2020; Han et al., 2020). Highly expressed circMYLK and circ0001429 in BC can enhance VEGFA gene expression by, respectively, sponging miR- 29a and miR-205-5p, resulting in enhanced tumor angiogenesis process (Zhong et al., 2017; Cao W. et al., 2019).

The ability to proliferate nearly infinity is a crucial trait of cancer cells, and the disturbance of the cell cycle acts as a vital role in the excessive proliferation of cancer cells (Sanli et al., 2017). With the expansion of ceRNA network research, a wealth of circRNAs have been found to regulate $\mathrm{BC}$ cell proliferation by influencing critical molecules of the cell cycle regulation. Circ0058063 functions as a competitive miR-145-5p sponge to restrain its freedom in the cytoplasm, which further leads to the release of cell cycle positively related gene CDK6 (Sun et al., 2019), thus increasing BC cell growth. In contrast, circNR3C1 is dramatically reduced in $\mathrm{BC}$, and it impairs the growth of $\mathrm{BC}$ tumor cells by restraining miR-27a-3p to inhibit its interactions with CCND1 and thus suppress cyclin D1 expression (Zheng et al., 2019). P21 (CDKN1A) and P27 (CDKN1B) are known as negative regulators that could induce cell cycle arrest at the G1/S phase and block tumor cell growth. Xie et al. (2018) demonstrated 


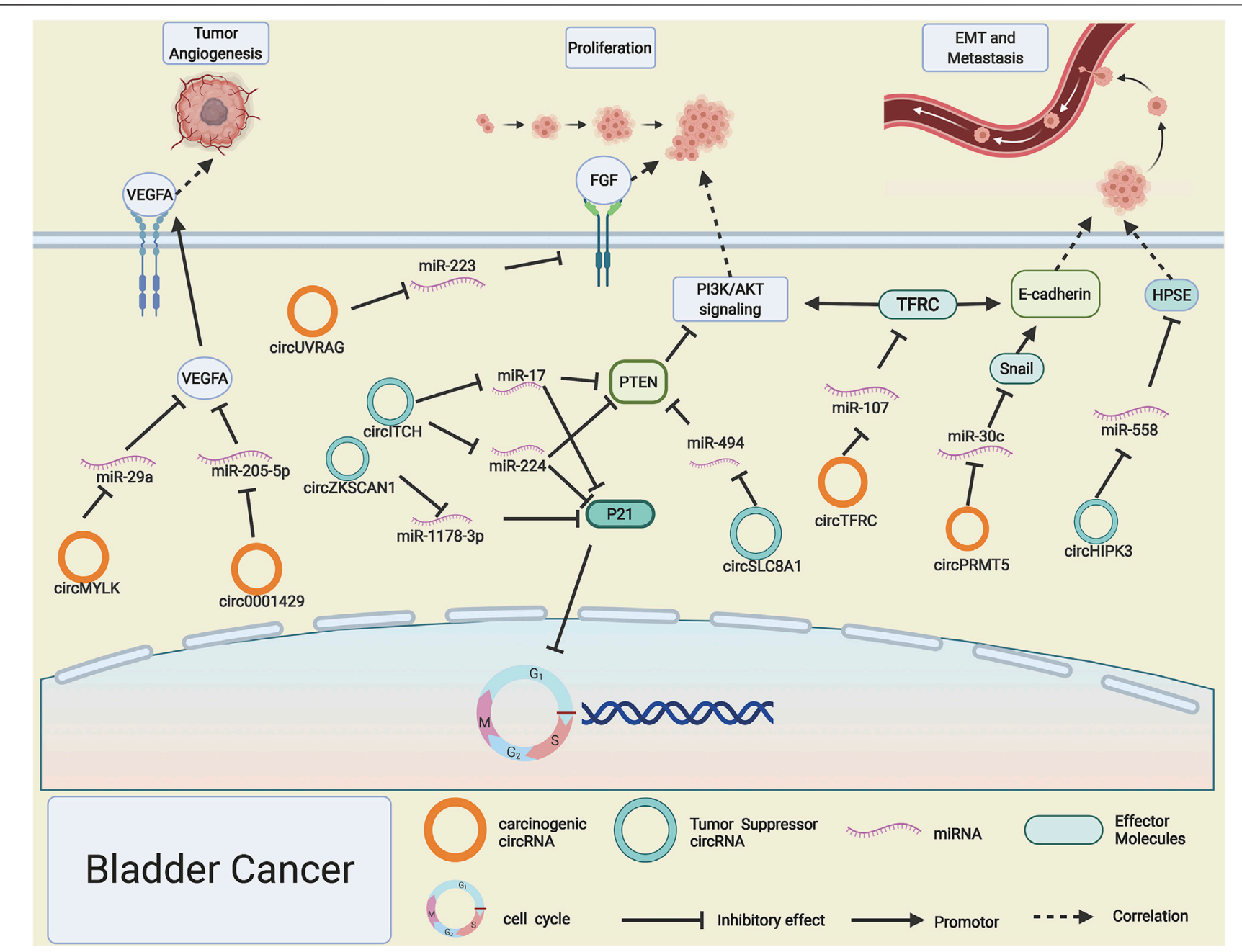

FIGURE 3 | Possible mechanisms of circRNAs in bladder cancer. Upregulated circMYLK, circ0001429, circUVRAG, circTFRC, and circPRMT5 (orange rings) and downregulated circHIPK3, circSLC8A1, circ-ITCH, and circ-ZKSCAN1 (cyan rings) regulate progression of bladder cancer by altering specific gene expression or tumorrelated signaling pathways.

that the BCRC-3 is downregulated in BC, which is capable of acting as a miR-182-5p sponge to influence the expression of $\mathrm{p} 27$, thus blocking the growth of BC cells. CircZKSCAN1 and circITCH boost the expression of $\mathrm{P} 21$, thus playing a role in $\mathrm{BC}$ inhibition by function as sponging for miR-1178-3p and miR224/miR-17. Simultaneously, circITCH can also enhance PTEN expression, an inhibitor of PI3K/AKT signaling, thus delaying the BC progression (Yang et al., 2018; Bi et al., 2019) (Figure 3).

\section{Prostate Cancer}

$\mathrm{PCa}$ is one of the most frequent malignancies with the highest newly diagnosed cases in men and ranked the second cancerrelated deaths worldwide (Fizazi et al., 2020). Although dramatic progress has been made in the diagnosis and treatment of $\mathrm{PCa}$, there is still a low overall survival rate among PCa patients. It is extremely vital to discover molecular diagnostic biomarkers and novel treatment targets related to the occurrence and progression of PCa. Like other cancers, circZNF609 is also highly expressed in
$\mathrm{PCa}$; it drives the progression of $\mathrm{PCa}$ by functioning as a competitive miR-186-5p sponge and giving rise to YAP1 upregulation and activating the AMPK signaling pathway (Jin et al., 2019). CircFOXO3 and circFMN2 can, respectively, sponge miR-29a-3p and miR-1238 and then release SLC25A15 and transcription factor LHX2, which drive the progression of PCa (Kong et al., 2020; Shan et al., 2020). However, when the expression level of circITCH in PCa is declined, the corresponding sponged miR-17-5p is released, which lead to the downregulated gene expression level of HOXB13 and significantly inhibit the development of PCa (Wang et al., 2019); intriguingly, HOXB13 was proved to be a pivotal upstream regulator of $\mathrm{AR}-\mathrm{V7}$ and participate in the development of castration-resistant prostate cancer (CRPC) (Chen Z. et al., 2018; Navarro and Goldstein, 2018). Like RCC (Han et al., 2020), circHIPK3 is also found to be overexpressed in $\mathrm{PCa}$; it can promote the proliferation and invasion potential of PCa cells through binding with miRNA-338-3p and enhancing 


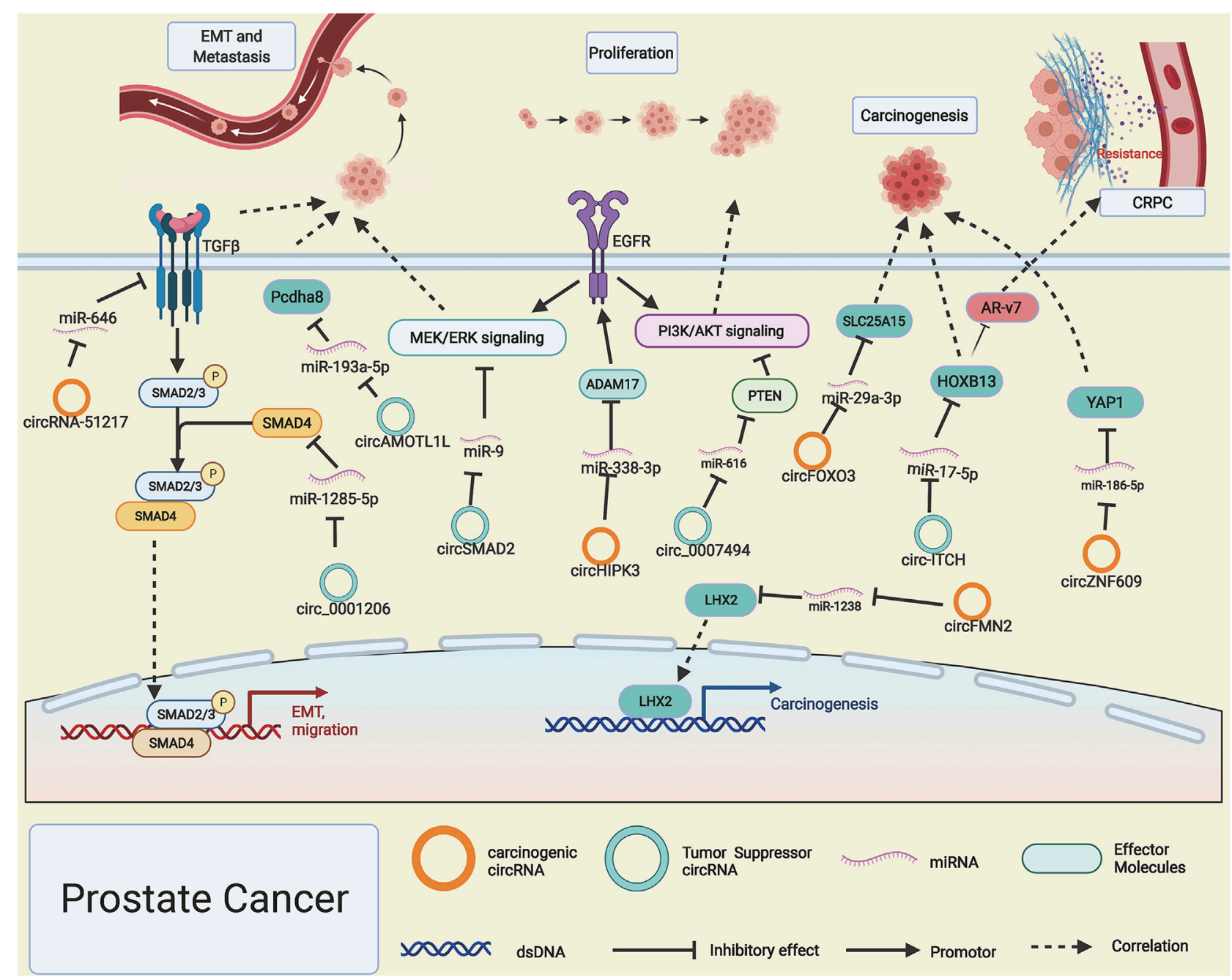

FIGURE 4 | Possible mechanisms of circRNAs in prostate cancer. Upregulated circRNA-51217, circZNF609, circHIPK3, circFMN2, and circFOXO3 (orange rings) and downregulated circ-ITCH, hsa_circ_0001206, circSMAD2, circAMOTL1L, and circ_0007494 (cyan rings) regulate progression of prostate cancer by altering specific gene expression or tumor-related signaling pathways.

the gene expression level of ADAM17, thus prompting the progression of PCa (Liu F. et al., 2020). However, lowly expressed circ_0007494 in PCa was reported to act as a molecular sponge for miR-616 and thus accelerate the expression of PTEN, which will block the PI3K/AKT signaling pathway, thus preventing tumor progression (Zhang et al., 2020).

The EMT process involves a series of changes such as critical gene expression patterns and cell proliferation, apoptosis, and migration. EMT-related genes' expression is regulated by intricate networks included but not limited to growth factors, transcription factors signaling pathways (Dongre and Weinberg, 2019). Xu et al. (2020) reported that R-2-hydroxyglutarate could enhance the expression level of circRNA-51217, which acts as a ceRNA to absorb miRNA-646 and leads to the upregulation of TGF- $\beta 1$, thus activating TGF- $\beta 1 / \mathrm{p}-\mathrm{Smad} 2 / 3$ signaling to enhance the abilities of PCa cell invasion. Furthermore, the androgen receptor (AR) could reverse this process by suppressing the expression of circ RNA-51217. In contrast, circ0001206 was found to function as a cancer suppressor by sponging miR1285-5p and subsequently boosting SMAD4 expression (Song et al., 2019), which is a well-known cancer suppressor gene in PCa. CircSMAD2, originated from SMAD2 gene transcripts, impedes the EMT process of PCa by sponging miR-9 and abating the phosphorylation of STAT3, MEK, and ERK (Han et al., 2019). Yang Z. et al. (2019) declared that p53/RBM25 signaling is involved in the biogenesis of circAMOTL1L, and downregulated circAMOTL1L leads to the upregulation of dissociative miR-193a-5p, thus inhibiting the expression of Pcdha8 and EMT process of PCa (Figure 4).

\section{CLINICAL APPLICATIONS OF CIRCULAR RNA IN UROLOGICAL CANCERS}

In the past few years, a good deal of dysregulated circRNAs have been reported in urinary tumors, including $\mathrm{RCC}, \mathrm{BC}$, and $\mathrm{PCa}$, 
TABLE 1 | CircRNAs act as biomarkers and therapeutic targets in urological cancers.

\begin{tabular}{|c|c|c|c|c|c|c|}
\hline Cancer type & circRNA & Dysregulation & $\begin{array}{l}\text { Sample } \\
\text { sources }\end{array}$ & Function & Clinicopathological association & References \\
\hline \multirow[t]{4}{*}{$\begin{array}{l}\text { Renal cell } \\
\text { carcinoma }\end{array}$} & hsa_circ_001895 & upregulated & tissue, cell lines & $\begin{array}{l}\text { prognostic marker and novel } \\
\text { ccRCC therapy }\end{array}$ & TNM stage, OS & $\begin{array}{l}\text { Chen et al. } \\
\text { (2020b) }\end{array}$ \\
\hline & circHIPK3 & upregulated & tissue, cell lines & $\begin{array}{l}\text { prognostic biomarker and target } \\
\text { for the molecular treatment of } \\
\text { ccRCC }\end{array}$ & $\begin{array}{l}\text { Tumor stage, grade and size, Overall } \\
\text { survival, ROC curve indicates AUC = } \\
0.95322\end{array}$ & $\begin{array}{l}\text { Han et al. } \\
(2020)\end{array}$ \\
\hline & cRAPGEF5 & $\begin{array}{l}\text { down- } \\
\text { regulated }\end{array}$ & tissue, cell lines & $\begin{array}{l}\text { prognostic biomarker and novel } \\
\text { therapeutic target for RCC } \\
\text { patients }\end{array}$ & $\begin{array}{l}\text { Tumor size, TNM stage, Metastasis, } \\
\text { OS, RFS }\end{array}$ & $\begin{array}{l}\text { Chen et al. } \\
\text { (2020a) }\end{array}$ \\
\hline & circHIAT1 & $\begin{array}{l}\text { down- } \\
\text { regulated }\end{array}$ & tissue, cell lines & $\begin{array}{l}\text { biomarker and potential new } \\
\text { therapy }\end{array}$ & Tumor stage, Metastasis, OS & $\begin{array}{l}\text { Wang et al. } \\
(2017 \mathrm{a})\end{array}$ \\
\hline \multirow[t]{7}{*}{$\begin{array}{l}\text { Bladder } \\
\text { cancer }\end{array}$} & hsa_circ_0137439 & upregulated & $\begin{array}{l}\text { urine, tissue, } \\
\text { cell lines }\end{array}$ & $\begin{array}{l}\text { independent prognostic } \\
\text { predicator }\end{array}$ & $\begin{array}{l}\text { Tumor stage, Tumor Grade, Lymph node } \\
\text { status, NMIBC/MIBC, OS, RFS }\end{array}$ & $\begin{array}{l}\text { Song et al. } \\
(2020)\end{array}$ \\
\hline & circPRMT5 & upregulated & $\begin{array}{l}\text { urine, plasma, } \\
\text { tissue, cell lines }\end{array}$ & $\begin{array}{l}\text { prognostic biomarker and } \\
\text { exploitable therapeutic target }\end{array}$ & $\begin{array}{l}\text { Clinical tumor stage, Tumor metastasis, } \\
\text { Survival }\end{array}$ & $\begin{array}{l}\text { Chen et al. } \\
\text { (2018a) }\end{array}$ \\
\hline & cTFRC & upregulated & tissue, cell lines & $\begin{array}{l}\text { potential marker of } \mathrm{BC} \text { diagnosis } \\
\text { or progression }\end{array}$ & $\begin{array}{l}\text { Tumor stage, Grade, Lymphatic invasion, } \\
\text { Survival }\end{array}$ & Su et al. (2019) \\
\hline & circRNA-MYLK & upregulated & tissue, cell lines & $\begin{array}{l}\text { promising target for } \mathrm{BC} \\
\text { diagnosis and therapy }\end{array}$ & Tumor stage, Overall survival & $\begin{array}{l}\text { Zhong et al. } \\
\text { (2017) }\end{array}$ \\
\hline & circ-BPTF & upregulated & tissue, cell lines & $\begin{array}{l}\text { potential biomarker and } \\
\text { therapeutic target }\end{array}$ & $\begin{array}{l}\text { Tumor grade, NMIBC/MIBC, Recurrence, } \\
\text { Overall survival }\end{array}$ & Bi et al. (2018) \\
\hline & circACVR2A & $\begin{array}{l}\text { down- } \\
\text { regulated }\end{array}$ & tissue, cell lines & $\begin{array}{l}\text { prognostic biomarker and } \\
\text { therapeutic target }\end{array}$ & $\begin{array}{l}\text { Clinicopathological characteristics, Overall } \\
\text { survival }\end{array}$ & $\begin{array}{l}\text { Dong et al. } \\
\text { (2019) }\end{array}$ \\
\hline & circ-ZKSCAN1 & $\begin{array}{l}\text { down- } \\
\text { regulated }\end{array}$ & tissue, cell lines & $\begin{array}{l}\text { promising marker and } \\
\text { therapeutic target }\end{array}$ & $\begin{array}{l}\text { Tumor grader, Stage, Lymph nodes } \\
\text { status, Recurrence, OS, DFS }\end{array}$ & Bi et al. (2019) \\
\hline \multirow[t]{4}{*}{$\begin{array}{l}\text { Prostate } \\
\text { cancer }\end{array}$} & circZMIZ1 & upregulated & $\begin{array}{l}\text { plasma, cell } \\
\text { lines }\end{array}$ & $\begin{array}{l}\text { novel biomarker and a treatment } \\
\text { target for prostate cancer }\end{array}$ & $\begin{array}{l}\text { correlated with the expression of } A R \text { and } \\
A R-V 7\end{array}$ & $\begin{array}{l}\text { Jiang et al. } \\
(2020)\end{array}$ \\
\hline & circAR3 & upregulated & $\begin{array}{l}\text { plasma, tissue, } \\
\text { cell lines }\end{array}$ & PCa biomarker & $\begin{array}{l}\text { PCa Gleason scores, lymph node } \\
\text { metastasis }\end{array}$ & $\begin{array}{l}\text { Luo et al. } \\
(2019)\end{array}$ \\
\hline & circFOXO3 & $\begin{array}{l}\text { down- } \\
\text { regulated }\end{array}$ & tissue, cell lines & $\begin{array}{l}\text { potential prognostic and } \\
\text { therapeutic approaches for } \\
\text { prostate cancer }\end{array}$ & $\begin{array}{l}\text { Tumor grade, chemoresistance to } \\
\text { docetaxel }\end{array}$ & $\begin{array}{l}\text { Shen et al. } \\
\text { (2020) }\end{array}$ \\
\hline & circRNA17 & $\begin{array}{l}\text { down- } \\
\text { regulated }\end{array}$ & tissue, cell lines & $\begin{array}{l}\text { a better therapy for } \\
\text { Enzalutamide resistance of } \mathrm{PCa}\end{array}$ & $\begin{array}{l}\text { PCa Gleason score, Enzalutamide } \\
\text { resistance }\end{array}$ & $\begin{array}{l}\text { Wu et al. } \\
(2019)\end{array}$ \\
\hline
\end{tabular}

RCC, renal cell carcinoma. ccRCC, clear cell renal cell carcinoma. BC, bladder cancer. PCa, prostate cancer. OS, overall survival. RFS, recurrence-free survival. DFS, disease-free survival. $R O C$, receiver operating characteristic curve. AUC, area under the curve. NMIBC, nonmuscle-invasive bladder cancer. MIBC, muscle-invasive bladder cancer. AR, androgen receptor. $A R-V 7$, androgen receptor splice variant 7.

and the expression level of these annotated circRNAs is closely linked to cancer stages, grades, and prognosis, indicating that circRNA can be used for diagnosis and treatment, some circRNAs that might act as biomarkers, and therapeutic targets are listed in Table 1.

\section{Circular RNAs Act as Diagnostic and Prognostic Biomarkers in Urological Cancers}

With the development of minimally invasive surgical techniques such as robotic surgeries, more and more surgical indications for urinary tumors have been expanded. Owing to a lack of credible and effective ways to early diagnosis, many patients with urinary tumors are still diagnosed with advanced cancer stages and miss the best chance for surgery, which underscores the urgent need for new biomarker detection in urinary cancers. Recently, the potential role of circRNAs as novel biomarkers has been increasingly recognized. Actually, due to their biological features such as high stability and specificity of tissue expression, circRNAs have been found to stably exist in human saliva, urine, and plasma (Wang S. et al., 2021); they are more likely to be ideal diagnostic and prognostic biomarkers. Song et al. (2020) applied microarray to identify differentially expressed circRNAs from 10 cases of BC urine samples and 10 normal urine samples. Subsequently, they discovered that hsa_circ_0137439 is remarkably overexpressed in BC patients' urine samples compared with normal people, which also had been validated in $116 \mathrm{BC}$ tissues and 30 normal tissues. Urinary hsa_circ_0137439 can distinguish not only BC and normal people but also muscle-invasive bladder cancer and nonmuscle invasive bladder cancer; in addition, the expression of has_circ_0137439 is closely associated with recurrence-free survival and overall survival of BC patients. At the mechanism level, hsa_circ_0137439 could function as a miR-142-5p sponge to decrease its expression and thus lead to upregulation of MTDH and promote $\mathrm{BC}$ progression, so they proposed that urinary hsa_circ_0137439 could be a new diagnostic and prognostic biomarker and treatment target in BC. Interestingly, Chen et al. (2018) found that circPRMT5 is significantly enriched in serum and urinary exosomes from nearly $100 \mathrm{BC}$ patients samples compared with corresponding normal people, and 
highly expressed circPRMT5 is in close contact with BC lymph node metastasis and advanced cancer progression. In addition, upregulated cTFRC, circ-BPTF, and downregulated circZKSCAN1 were also identified as promising diagnostic and prognostic biomarkers in BC (Bi et al., 2018; Bi et al., 2019; Su et al., 2019). Cao S. et al. (2019) comprehensively analyzed exome-RNA-seq from 47 cases of metastatic CRPC samples, and RNase $\mathrm{R}$ treated RNA-seq of patient-derived xenografts and cell models, then they validated 13 circRNAs derived from the $\mathrm{AR}$ in $\mathrm{PCa}$, due to the high detectability of these AR-originated circRNAs in PCa patient plasma; they proposed that these AR-originated circRNAs may serve as alternative circulatory biomarkers for AR expression and CRPC progression. Intriguingly, Luo et al. (2019) also identified an AR-derived circRNA circAR3, which is extremely upregulated in PCa patients' plasma, especially in advanced $\mathrm{PCa}$ patients. Additionally, they cannot be measured in patients' plasma after receiving radical prostatectomy; thus, they proposed that circAR3 is a promising biomarker in PCa. Meanwhile, some researchers reported that circZMIZ1 is highly expressed in PC patients' plasma and tissues compared with counterparts of $\mathrm{BPH}$ patients; circZMIZ1 drives the development of PCa by enhancing the expression levels of AR and AR splice variant 7 (Jiang et al., 2020). Chen et al. (2020) found that cRAPGEF5 is dramatically suppressed in RCC tissues compared with adjacent nontumorous tissues, and among 245 cases of RCC, cRAPGEF5 reduction is closely associated with advanced clinical traits and can be an independent predictor for poor overall survival and recurrence-free survival in RCC. Moreover, an upregulated circular RNA in RCC tissues, circHIPK3, has been found to be positively associated with cancer stages, grades, and survival, and the receiver operating characteristic curve analysis indicated that circHIPK3 is a promising molecule marker in RCC (AUC = 0.95322, 95\%CI: 0.9119-0.9945) (Han et al., 2020). Franz et al. (2019) proposed that circEGLN3 can act as a potential biomarker and discriminate malignant RCC from normal with an accuracy rate of $97 \%$.

\section{Therapeutic Potential of Circular RNAs in Urological Cancers}

As described earlier, the dysregulation of circRNAs may affect cancer cell proliferation, invasion, migration, angiogenesis, apoptosis, or drug resistance, thereby affecting the progression of a diversity of cancer. The advantage for targeting circRNA treatment lies in its potential of low off-target effects, whereas microRNAs and small interference RNAs have higher off-target effects owing to their short length and half-life. Recently, some researchers have artificially synthesized circRNAs (also named artificial sponges) to attenuate cardiac hypertrophy (Lavenniah et al., 2020) and suppress gastric carcinoma cell proliferation (Liu et al., 2018). These results suggest that it will be possible to treat urinary tumors by targeting circRNA. Chen Z. et al. (2020) illustrated that hsa_circ_001895 is upregulated in RCC tissues and cell lines; they utilized RNAi technology to silence the expression of has_circ_001895 and suppress tumor proliferation and metastasis in vivo and in vitro. Wang $K$. et al. (2017) found that AR can enhance ccRCC cell invasion and migration, whereas circHIAT1 can reverse this process, which may help us develop potential new treatments to inhibit ccRCC metastasis. Dong et al. (2019) research showed that circACVR2A is significantly downregulated in BC tissues and cell lines; overexpression of circACVR2A can dramatically restrain the proliferation and metastasis of $\mathrm{BC}$. Meanwhile, upregulation of circRNA-MYLK was found to accelerate growth, angiogenesis, and migration of $\mathrm{BC}$ cell lines and xenografts in the study of Zhong et al. (2017); silencing the expression of circRNA-MYLK can inhibit the development of BC, which also indicated a potential therapeutic target for $\mathrm{BC}$. $\mathrm{Wu}$ et al. (2019) preclinical study showed that circRNA17 could change the enzalutamide sensitivity and cell migration ability of CRPC cells by activating the miR-181c-5p/ARv7 signaling pathway, and this signaling pathway can be a better treatment method for enzalutamide-resistant CRPC. Shen et al. (2020) reported that circFOXO3 is significantly decreased in $\mathrm{PCa}$ patients, especially in advanced PCa patients, and disturbing the expression of circFoxo3 could accelerate PCa cells proliferation, metastasis, and chemotherapy resistance to docetaxel, which suggested that targeting circFoxo3 may be a viable strategy for $\mathrm{PCa}$, especially for patients with docetaxel resistance. Given the crucial roles of circRNAs in the origination and development of urological cancers, it is reasonable to believe that circRNAs could be potential clinical therapeutic targets in the future.

\section{CONCLUSION AND PERSPECTIVES}

CircRNAs were initially regarded as nonfunctional "junks" generated by abnormal splicing events (Gao et al., 2016); with the recognition of novel RNA splicing events such as backsplicing and alternative splicing mechanisms, more and more functional circRNAs were identified, and plentiful researches elucidated that circRNAs are involved in diverse biological processes and disease progression, especially the genesis and development of human cancers. Urological cancers such as RCC, BC, and PCa were complicated diseases with high mortality and threatened human health. Therefore, a comprehensive review of the biogenesis, properties of circRNA, and its molecular mechanisms and clinical applications in urinary cancers may be helpful for the development of effective anticancer measures.

With the rapid development of high-throughput sequencing technology, plentiful circRNAs have been discovered, annotated, and functionally predicted (Fan et al., 2015). Owing to the special ring structure of circRNA and the high similarity of diverse transcript sequences of the same parental gene, the circRNA sequencing test usually has low accuracy and high false-positive rates; at this point, the process of circRNA validation is particularly important. However, many studies lack sufficient validations for circRNA; the main validation methods should include RT-PCR, sanger sequencing, Northern blot, RNA-FISH technologies, etc. (Kristensen et al., 2019). At the molecular mechanisms layer, so far, most studies of circRNAs have 
focused on miRNA sponges; the interactions between circRNAs and other novel mechanisms are still less. For example, do circRNAs regulate tumor progression by affecting novel cell programmed deaths such as ferroptosis, pyroptosis? The potential roles of circRNAs in the urinary tumor microenvironment remain unknown.

The ultimate goal of medical research is to improve survival; owing to the high stability and tissue-specific expression pattern of circRNAs, they have great potentials as molecular biomarkers and therapeutic targets. However, the samples of current researches are mainly derived from cancer tissues and cells; noninvasive samples such as urine, blood, and saliva were rarely applied to basic research. Additionally, for the purpose of treatment, the expression level of circRNAs needs to be controlled effectively; whether advanced technologies such as CRISPR-Cas-based editor systems can be applied to change the production of circRNAs without affecting their linear transcripts is also unclear. In brief, deep basic researches are needed to elucidate the underlying mechanisms, and reliable clinical studies are required to further validate the effectiveness

\section{REFERENCES}

Aktaş, T., Avşar Ilık, İ., Maticzka, D., Bhardwaj, V., Pessoa Rodrigues, C., Mittler, G., et al. (2017). DHX9 Suppresses RNA Processing Defects Originating from the Alu Invasion of the Human Genome. Nature 544 (7648), 115-119. doi:10.1038/nature21715

Barone, M. A., Widmer, M., Arrowsmith, S., Ruminjo, J., Seuc, A., Landry, E., et al. (2015). Breakdown of Simple Female Genital Fistula Repair after 7 Day versus 14 Day Postoperative Bladder Catheterisation: a Randomised, Controlled, Open-Label, Non-inferiority Trial. The Lancet 386 (9988), 56-62. doi:10.1016/s0140-6736(14)62337-0

Bi, J., Liu, H., Cai, Z., Dong, W., Jiang, N., Yang, M., et al. (2018). Circ-BPTF Promotes Bladder Cancer Progression and Recurrence through the miR-31-5p/ RAB27A axis. Aging 10 (8), 1964-1976. doi:10.18632/aging.101520

Bi, J., Liu, H., Dong, W., Xie, W., He, Q., Cai, Z., et al. (2019). Circular RNA CircZKSCAN1 Inhibits Bladder Cancer Progression through miR-1178-3p/p21 axis and Acts as a Prognostic Factor of Recurrence. Mol. Cancer 18 (1), 133. doi:10.1186/s12943-019-1060-9

Boley, N., Stoiber, M. H., Booth, B. W., Wan, K. H., Hoskins, R. A., Bickel, P. J., et al. (2014). Genome-guided Transcript Assembly by Integrative Analysis of RNA Sequence Data. Nat. Biotechnol. 32 (4), 341-346. doi:10.1038/nbt.2850

Cao, S., Ma, T., Ungerleider, N., Roberts, C., Kobelski, M., Jin, L., et al. (2019a). Circular RNAs Add Diversity to Androgen Receptor Isoform Repertoire in Castration-Resistant Prostate Cancer. Oncogene 38 (45), 7060-7072. doi:10.1038/s41388-019-0947-7

Cao, W., Zhao, Y., Wang, L., and Huang, X. (2019b). Circ0001429 Regulates Progression of Bladder Cancer through Binding miR-205-5p and Promoting VEGFA Expression. Cbm 25 (1), 101-113. doi:10.3233/cbm-182380

Capel, B., Swain, A., Nicolis, S., Hacker, A., Walter, M., Koopman, P., et al. (1993). Circular Transcripts of the Testis-Determining Gene Sry in Adult Mouse Testis. Cell 73 (5), 1019-1030. doi:10.1016/0092-8674(93)90279-y

Chen, I., Chen, C.-Y., and Chuang, T.-J. (2015). Biogenesis, Identification, and Function of Exonic Circular RNAs. WIREs RNA 6 (5), 563-579. doi:10.1002/ wrna.1294

Chen, L.-L. (2016). The Biogenesis and Emerging Roles of Circular RNAs. Nat. Rev. Mol. Cel Biol 17 (4), 205-211. doi:10.1038/nrm.2015.32

Chen, L.-L. (2020). The Expanding Regulatory Mechanisms and Cellular Functions of Circular RNAs. Nat. Rev. Mol. Cel Biol 21 (8), 475-490. doi:10.1038/s41580020-0243-y

Chen, Q., Liu, T., Bao, Y., Zhao, T., Wang, J., Wang, H., et al. (2020a). CircRNA cRAPGEF5 Inhibits the Growth and Metastasis of Renal Cell Carcinoma via the of clinical applications of circRNAs. So that these findings can solve the actual clinical problems, thus improving the diagnosis and treatment in the future. CircRNAs are of great importance in the occurrence and development of urological cancers; we hope that with the development of biotechnology and basic research, more and more annotated circRNAs can be discovered and applied to clinical treatment.

\section{AUTHOR CONTRIBUTIONS}

SW drafted and wrote the manuscript. YY, WW, and XM collected the related papers. XW and LX revised the manuscript. All authors read and approved the final manuscript.

\section{FUNDING}

This study was supported by the National Natural Science Foundation of China, grant/award number: 81802564 .

miR-27a-3p/TXNIP Pathway. Cancer Lett. 469, 68-77. doi:10.1016/ j.canlet.2019.10.017

Chen, S., Huang, V., Xu, X., Livingstone, J., Soares, F., Jeon, J., et al. (2019a). Widespread and Functional RNA Circularization in Localized Prostate Cancer. Cell 176 (4), 831-e22. doi:10.1016/j.cell.2019.01.025

Chen, T., Shao, S., Li, W., Liu, Y., and Cao, Y. (2019b). The Circular RNA Hsa-Circ0072309 Plays Anti-tumour Roles by Sponging miR-100 through the Deactivation of PI3K/AKT and mTOR Pathways in the Renal Carcinoma Cell Lines. Artif. Cell nanomedicine, Biotechnol. 47 (1), 3638-3648. doi:10.1080/ 21691401.2019.1657873

Chen, X., Chen, R.-X., Wei, W.-S., Li, Y.-H., Feng, Z.-H., Tan, L., et al. (2018a). PRMT5 Circular RNA Promotes Metastasis of Urothelial Carcinoma of the Bladder through Sponging miR-30c to Induce Epithelial-Mesenchymal Transition. Clin. Cancer Res. 24 (24), 6319-6330. doi:10.1158/10780432.Ccr-18-1270

Chen, Z., Lu, T., Huang, L., Wang, Z., Yan, Z., Guan, Y., et al. (2021). Circular RNA Cia-MAF Drives Self-Renewal and Metastasis of Liver Tumor-Initiating Cells via Transcription Factor MAFF. J. Clin. Invest. 131. doi:10.1172/jci148020

Chen, Z., Wu, D., Thomas-Ahner, J. M., Lu, C., Zhao, P., Zhang, Q., et al. (2018b). Diverse AR-V7 Cistromes in Castration-Resistant Prostate Cancer Are Governed by HoxB13. Proc. Natl. Acad. Sci. USA 115 (26), 6810-6815. doi:10.1073/pnas.1718811115

Chen, Z., Xiao, K., Chen, S., Huang, Z., Ye, Y., and Chen, T. (2020b). Circular RNA Hsa_circ_001895 Serves as a Sponge of microRNA-296-5p to Promote clear Cell Renal Cell Carcinoma Progression by Regulating SOX12. Cancer Sci. 111 (2), 713-726. doi:10.1111/cas.14261

Conn, S. J., Pillman, K. A., Toubia, J., Conn, V. M., Salmanidis, M., Phillips, C. A., et al. (2015). The RNA Binding Protein Quaking Regulates Formation of circRNAs. Cell 160 (6), 1125-1134. doi:10.1016/j.cell.2015.02.014

Dong, W., Bi, J., Liu, H., Yan, D., He, Q., Zhou, Q., et al. (2019). Circular RNA ACVR2A Suppresses Bladder Cancer Cells Proliferation and Metastasis through miR-626/EYA4 axis. Mol. Cancer 18 (1), 95. doi:10.1186/s12943019-1025-Z

Dongre, A., and Weinberg, R. A. (2019). New Insights into the Mechanisms of Epithelial-Mesenchymal Transition and Implications for Cancer. Nat. Rev. Mol. Cel Biol 20 (2), 69-84. doi:10.1038/s41580-018-0080-4

Dube, U., Del-Aguila, J., Del-Aguila, J. L., Li, Z., Budde, J. P., Jiang, S., et al. (2019). An Atlas of Cortical Circular RNA Expression in Alzheimer Disease Brains Demonstrates Clinical and Pathological Associations. Nat. Neurosci. 22 (11), 1903-1912. doi:10.1038/s41593-019-0501-5

Enuka, Y., Lauriola, M., Feldman, M. E., Sas-Chen, A., Ulitsky, I., and Yarden, Y. (2016). Circular RNAs Are Long-Lived and Display Only Minimal Early 
Alterations in Response to a Growth Factor. Nucleic Acids Res. 44 (3), 1370-1383. doi:10.1093/nar/gkv1367

Fan, X., Zhang, X., Wu, X., Guo, H., Hu, Y., Tang, F., et al. (2015). Single-cell RNASeq Transcriptome Analysis of Linear and Circular RNAs in Mouse Preimplantation Embryos. Genome Biol. 16, 148. doi:10.1186/s13059-0150706-1

Fei, T., Chen, Y., Xiao, T., Li, W., Cato, L., Zhang, P., et al. (2017). Genome-wide CRISPR Screen Identifies HNRNPL as a Prostate Cancer Dependency Regulating RNA Splicing. Proc. Natl. Acad. Sci. USA 114 (26), 201617467-E5215. doi:10.1073/pnas.1617467114

Feng, J., Chen, W., Dong, X., Wang, J., Mei, X., Deng, J., et al. (2021). CSCD2: an Integrated Interactional Database of Cancer-specific Circular RNAs. Nucleic Acids Res. doi:10.1093/nar/gkab830

Fizazi, K., Shore, N., Tammela, T. L., Ulys, A., Vjaters, E., Polyakov, S., et al. (2020). Nonmetastatic, Castration-Resistant Prostate Cancer and Survival with Darolutamide. N. Engl. J. Med. 383 (11), 1040-1049. doi:10.1056/ NEJMoa2001342

Franco-Zorrilla, J. M., Valli, A., Todesco, M., Mateos, I., Puga, M. I., RubioSomoza, I., et al. (2007). Target Mimicry Provides a New Mechanism for Regulation of microRNA Activity. Nat. Genet. 39 (8), 1033-1037. doi:10.1038/ ng2079

Franz, A., Ralla, B., Weickmann, S., Jung, M., Rochow, H., Stephan, C., et al. (2019). Circular RNAs in Clear Cell Renal Cell Carcinoma: Their Microarray-Based Identification, Analytical Validation, and Potential Use in a Clinico-Genomic Model to Improve Prognostic Accuracy. Cancers 11 (10), 1473. doi:10.3390/ cancers 11101473

Gao, L., Tang, X., He, Q., Sun, G., Wang, C., and Qu, H. (2021a). Exosometransmitted circCOG2 Promotes Colorectal Cancer Progression via miR-1305/ tgf-B2/smad3 Pathway. Cell Death Discov. 7 (1), 281. doi:10.1038/s41420-02100680-0

Gao, X., Xia, X., Li, F., Zhang, M., Zhou, H., Wu, X., et al. (2021b). Circular RNAEncoded Oncogenic E-Cadherin Variant Promotes Glioblastoma Tumorigenicity through Activation of EGFR-STAT3 Signalling. Nat. Cel Biol 23 (3), 278-291. doi:10.1038/s41556-021-00639-4

Gao, Y., Wang, J., Zheng, Y., Zhang, J., Chen, S., and Zhao, F. (2016). Comprehensive Identification of Internal Structure and Alternative Splicing Events in Circular RNAs. Nat. Commun. 7, 12060. doi:10.1038/ncomms 12060

Guarnerio, J., Zhang, Y., Cheloni, G., Panella, R., Mae Katon, J., Simpson, M., et al. (2019). Intragenic Antagonistic Roles of Protein and circRNA in Tumorigenesis. Cell Res 29 (8), 628-640. doi:10.1038/s41422-019-0192-1

Han, B., Shaolong, E., Luan, L., Li, N., and Liu, X. (2020). CircHIPK3 Promotes Clear Cell Renal Cell Carcinoma (ccRCC) Cells Proliferation and Metastasis via Altering of miR-508-3p/CXCL13 Signal. Ott Vol. 13, 6051-6062. doi:10.2147/ ott.S251436

Han, N., Ding, L., Wei, X., Fan, L., and Yu, L. (2019). Retracted : circSMAD2 Governs Migration and Epithelial-Mesenchymal Transition by Inhibiting microRNA-9. J. Cel Biochem 122, 1253. doi:10.1002/jcb.29638

Han, Z., Zhang, Y., Sun, Y., Chen, J., Chang, C., Wang, X., et al. (2018). Er $\beta$ Mediated Alteration of circATP2B1 and miR-204-3p Signaling Promotes Invasion of Clear Cell Renal Cell Carcinoma. Cancer Res. 78 (10), 2550-2563. doi:10.1158/0008-5472.Can-17-1575

Hansen, T. B., Wiklund, E. D., Bramsen, J. B., Villadsen, S. B., Statham, A. L., Clark, S. J., et al. (2011). miRNA-dependent Gene Silencing Involving Ago2-Mediated Cleavage of a Circular Antisense RNA. EMBO J. 30 (21), 4414-4422. doi:10.1038/emboj.2011.359

Huang, C., Liang, D., Tatomer, D. C., and Wilusz, J. E. (2018). A Length-dependent Evolutionarily Conserved Pathway Controls Nuclear export of Circular RNAs. Genes Dev. 32, 639-644. doi:10.1101/gad.314856.118

Huang, S., Li, X., Zheng, H., Si, X., Li, B., Wei, G., et al. (2019). Loss of Superenhancer-regulated circRNA Nfix Induces Cardiac Regeneration after Myocardial Infarction in Adult Mice. Circulation 139 (25), 2857-2876. doi:10.1161/circulationaha.118.038361

Jeck, W. R., Sorrentino, J. A., Wang, K., Slevin, M. K., Burd, C. E., Liu, J., et al. (2013). Circular RNAs Are Abundant, Conserved, and Associated with ALU Repeats. Rna 19 (2), 141-157. doi:10.1261/rna.035667.112

Jiang, H., Lv, D. J., Song, X. L., Wang, C., Yu, Y. Z., and Zhao, S. C. (2020). Upregulated circZMIZ1 Promotes the Proliferation of Prostate Cancer Cells and Is a Valuable Marker in Plasma. neo 67 (1), 68-77. doi:10.4149/ neo_2019_190213N116

Jiang, T., Xia, Y., Lv, J., Li, B., Li, Y., Wang, S., et al. (2021a). A Novel Protein Encoded by circMAPK1 Inhibits Progression of Gastric Cancer by Suppressing Activation of MAPK Signaling. Mol. Cancer 20 (1), 66. doi:10.1186/s12943-02101358-y

Jiang, Z., Hou, Z., Li, L., Liu, W., Yu, Z., and Chen, S. (2021b). Exosomal circEPB41L2 Serves as a Sponge for miR-21-5p and miR-942-5p to Suppress Colorectal Cancer Progression by Regulating the PTEN/AKT Signalling Pathway. Eur. J. Clin. Invest. 51, e13581. doi:10.1111/eci.13581

Jin, C., Zhao, W., Zhang, Z., and Liu, W. (2019). Silencing Circular RNA circZNF609 Restrains Growth, Migration and Invasion by Up-Regulating microRNA-186-5p in Prostate Cancer. Artif. Cell nanomedicine, Biotechnol. 47 (1), 3350-3358. doi:10.1080/21691401.2019.1648281

Kong, Z., Wan, X., Lu, Y., Zhang, Y., Huang, Y., Xu, Y., et al. (2020). Circular RNA circFOXO3 Promotes Prostate Cancer Progression through Sponging miR-29a3p. J. Cel Mol Med 24 (1), 799-813. doi:10.1111/jcmm.14791

Kristensen, L. S., Andersen, M. S., Stagsted, L. V. W., Ebbesen, K. K., Hansen, T. B., and Kjems, J. (2019). The Biogenesis, Biology and Characterization of Circular RNAs. Nat. Rev. Genet. 20 (11), 675-691. doi:10.1038/s41576-019-0158-7

Lavenniah, A., Luu, T. D. A., Li, Y. P., Lim, T. B., Jiang, J., Ackers-Johnson, M., et al. (2020). Engineered Circular RNA Sponges Act as miRNA Inhibitors to Attenuate Pressure Overload-Induced Cardiac Hypertrophy. Mol. Ther. 28 (6), 1506-1517. doi:10.1016/j.ymthe.2020.04.006

Li, C., Zhang, J., Yang, X., Hu, C., Chu, T., Zhong, R., et al. (2021a). hsa_circ_0003222 Accelerates Stemness and Progression of Non-small Cell Lung Cancer by Sponging miR-527. Cell Death Dis 12 (9), 807. doi:10.1038/ s41419-021-04095-8

Li, J., Huang, C., Zou, Y., Ye, J., Yu, J., and Gui, Y. (2020a). CircTLK1 Promotes the Proliferation and Metastasis of Renal Cell Carcinoma by Sponging miR-136-5p. Mol. Cancer 19 (1), 103. doi:10.1186/s12943-020-01225-2

Li, J., Xu, X., Meng, S., Liang, Z., Wang, X., Xu, M., et al. (2017a). MET/SMAD3/ SNAIL Circuit Mediated by miR-323a-3p Is Involved in Regulating EpithelialMesenchymal Transition Progression in Bladder Cancer. Cel Death Dis 8 (8), e3010. doi:10.1038/cddis.2017.331

Li, T., Sun, X., and Chen, L. (2020b). Exosome Circ_0044516 Promotes Prostate Cancer Cell Proliferation and Metastasis as a Potential Biomarker. J. Cel Biochem 121 (3), 2118-2126. doi:10.1002/jcb.28239

Li, W., Song, Y. Y. Y., Rao, T., Yu, W. M., Ruan, Y., Ning, J. Z., et al. (2021b). CircCSNK1G3 Up-regulates miR-181b to Promote Growth and Metastasis via TIMP3-mediated Epithelial to Mesenchymal Transitions in Renal Cell Carcinoma. J. Cel. Mol. Med. doi:10.1111/jcmm.15911

Li, X., Zhang, J.-L., Lei, Y.-N., Liu, X.-Q., Xue, W., Zhang, Y., et al. (2021c). Linking Circular Intronic RNA Degradation and Function in Transcription by RNase H1. Sci. China Life Sci.Life sciences. doi:10.1007/s11427-021-1993-6

Li, Y., Zheng, F., Xiao, X., Xie, F., Tao, D., Huang, C., et al. (2017b). Circ HIPK 3 Sponges miR-558 to Suppress Heparanase Expression in Bladder Cancer Cells. EMBO Rep. 18 (9), 1646-1659. doi:10.15252/embr.201643581

Li, Y., Zheng, Q., Bao, C., Li, S., Guo, W., Zhao, J., et al. (2015a). Circular RNA Is Enriched and Stable in Exosomes: a Promising Biomarker for Cancer Diagnosis. Cel Res 25 (8), 981-984. doi:10.1038/cr.2015.82

Li, Z., Huang, C., Bao, C., Chen, L., Lin, M., Wang, X., et al. (2015b). Exon-intron Circular RNAs Regulate Transcription in the Nucleus. Nat. Struct. Mol. Biol. 22 (3), 256-264. doi:10.1038/nsmb.2959

Liu, F., Fan, Y., Ou, L., Li, T., Fan, J., Duan, L., et al. (2020a). CircHIPK3 Facilitates the G2/M Transition in Prostate Cancer Cells by Sponging miR-338-3p. Ott Vol. 13, 4545-4558. doi:10.2147/ott.S242482

Liu, H., Hu, G., Wang, Z., Liu, Q., Zhang, J., Chen, Y., et al. (2020b). circPTCH1 Promotes Invasion and Metastasis in Renal Cell Carcinoma via Regulating miR485-5p/MMP14 axis. Theranostics 10 (23), 10791-10807. doi:10.7150/ thno. 47239

Liu, X., Abraham, J. M., Cheng, Y., Wang, Z., Wang, Z., Zhang, G., et al. (2018). Synthetic Circular RNA Functions as a miR-21 Sponge to Suppress Gastric Carcinoma Cell Proliferation. Mol. Ther. - Nucleic Acids 13, 312-321. doi:10.1016/j.omtn.2018.09.010

Lu, Q., Liu, T., Feng, H., Yang, R., Zhao, X., Chen, W., et al. (2019). Circular RNA circSLC8A1 Acts as a Sponge of miR-130b/miR-494 in Suppressing Bladder 
Cancer Progression via Regulating PTEN. Mol. Cancer 18 (1), 111. doi:10.1186/ s12943-019-1040-0

Luigi, M., Hoefnagel, S. J. M., Domenico, Z., Marian, V. D. M., Peter, V. E., Silvia, C., et al. (2018). microRNA 125a Regulates MHC-I Expression on Esophageal Adenocarcinoma Cells, Associated with Suppression of Anti-tumor Immune Response and Poor Outcomes of Patients. Gastroenterology. S0016508518346407.

Luo, J., Li, Y., Zheng, W., Xie, N., Shi, Y., Long, Z., et al. (2019). Characterization of a Prostate- and Prostate Cancer-specific Circular RNA Encoded by the Androgen Receptor Gene. Mol. Ther. - Nucleic Acids 18, 916-926. doi:10.1016/j.omtn.2019.10.015

Memczak, S., Jens, M., Elefsinioti, A., Torti, F., Krueger, J., Rybak, A., et al. (2013). Circular RNAs Are a Large Class of Animal RNAs with Regulatory Potency. Nature 495 (7441), 333-338. doi:10.1038/nature11928

Navarro, H. I., and Goldstein, A. S. (2018). HoxB13 Mediates AR-V7 Activity in Prostate Cancer. Proc. Natl. Acad. Sci. USA 115 (26), 6528-6529. doi:10.1073/ pnas. 1808196115

Park, O. H., Ha, H., Lee, Y., Boo, S. H., Kwon, D. H., Song, H. K., et al. (2019). Endoribonucleolytic Cleavage of m6A-Containing RNAs by RNase P/MRP Complex. Mol. Cel. 74 (3), 494-507.e498. doi:10.1016/j.molcel.2019.02.034

Rajappa, A., Banerjee, S., Sharma, V., and Khandelia, P. (2020). Circular RNAs: Emerging Role in Cancer Diagnostics and Therapeutics. Front. Mol. Biosci. 7, 577938. doi:10.3389/fmolb.2020.577938

Reese, M., and Dhayat, S. A. (2021). Small Extracellular Vesicle Non-coding RNAs in Pancreatic Cancer: Molecular Mechanisms and Clinical Implications. J. Hematol. Oncol. 14 (1), 141. doi:10.1186/s13045-021-01149-4

Rybak-Wolf, A., Stottmeister, C., Glažar, P., Jens, M., Pino, N., Giusti, S., et al. (2015). Circular RNAs in the Mammalian Brain Are Highly Abundant, Conserved, and Dynamically Expressed. Mol. Cel. 58 (5), 870-885. doi:10.1016/j.molcel.2015.03.027

Salmena, L., Poliseno, L., Tay, Y., Kats, L., and Pandolfi, P. P. (2011). A ceRNA Hypothesis: the Rosetta Stone of a Hidden RNA Language. Cell 146 (3), 353-358. doi:10.1016/j.cell.2011.07.014

Salzman, J., Chen, R. E., Olsen, M. N., Wang, P. L., and Brown, P. O. (2013). Celltype Specific Features of Circular RNA Expression. Plos Genet. 9 (9), e1003777. doi:10.1371/journal.pgen.1003777

Sanli, O., Dobruch, J., Knowles, M. A., Burger, M., Alemozaffar, M., Nielsen, M. E., et al. (2017). Bladder Cancer. Nat. Rev. Dis. Primers 3, 17022. doi:10.1038/ nrdp.2017.22

Shan, G., Shao, B., Liu, Q., Zeng, Y., Fu, C., Chen, A., et al. (2020). circFMN2 Sponges miR-1238 to Promote the Expression of LIM-Homeobox Gene 2 in Prostate Cancer Cells. Mol. Ther. - Nucleic Acids 21, 133-146. doi:10.1016/ j.omtn.2020.05.008

Shen, Z., Zhou, L., Zhang, C., and Xu, J. (2020). Reduction of Circular RNA Foxo3 Promotes Prostate Cancer Progression and Chemoresistance to Docetaxel. Cancer Lett. 468, 88-101. doi:10.1016/j.canlet.2019.10.006

Shi, X., Wang, B., Feng, X., Xu, Y., Lu, K., and Sun, M. (2020). circRNAs and Exosomes: A Mysterious Frontier for Human Cancer. Mol. Ther. - Nucleic Acids 19, 384-392. doi:10.1016/j.omtn.2019.11.023

Siegel, R. L., Miller, K. D., and Jemal, A. (2020). Cancer Statistics, 2020. CA A. Cancer J. Clin. 70 (1), 7-30. doi:10.3322/caac.21590

Slack, F. J., and Chinnaiyan, A. M. (2019). The Role of Non-coding RNAs in Oncology. Cell 179 (5), 1033-1055. doi:10.1016/j.cell.2019.10.017

Song, Z., Zhang, Q., Zhu, J., Yin, G., Lin, L., and Liang, C. (2020). Identification of Urinary Hsa_circ_0137439 as a Potential Biomarker and Tumor Regulator of Bladder Cancer. neo 67 (1), 137-146. doi:10.4149/neo_2018_181214N970

Song, Z., Zhuo, Z., Ma, Z., Hou, C., Chen, G., and Xu, G. (2019). Hsa_Circ_0001206 Is Downregulated and Inhibits Cell Proliferation, Migration and Invasion in Prostate Cancer. Artif. Cell nanomedicine, Biotechnol. 47 (1), 2449-2464. doi:10.1080/21691401.2019.1626866

Su, H., Tao, T., Yang, Z., Kang, X., Zhang, X., Kang, D., et al. (2019). Circular RNA cTFRC Acts as the Sponge of MicroRNA-107 to Promote Bladder Carcinoma Progression. Mol. Cancer 18 (1), 27. doi:10.1186/s12943-0190951-0

Sun, M., Zhao, W., Chen, Z., Li, M., Li, S., Wu, B., et al. (2019). Circ_0058063 Regulates CDK6 to Promote Bladder Cancer Progression by Sponging miR145-5p. J. Cel Physiol 234 (4), 4812-4824. doi:10.1002/jcp.27280
Tay, Y., Kats, L., Salmena, L., Weiss, D., Tan, S. M., Ala, U., et al. (2011). CodingIndependent Regulation of the Tumor Suppressor PTEN by Competing Endogenous mRNAs. Cell 147 (2), 344-357. doi:10.1016/j.cell.2011.09.029

Tay, Y., Rinn, J., and Pandolfi, P. P. (2014). The Multilayered Complexity of ceRNA Crosstalk and Competition. Nature 505 (7483), 344-352. doi:10.1038/ nature 12986

Tian, Y., Gao, P., Dai, D., Chen, L., Chu, X., and Mei, X. (2021). Circular RNA circSETD3 Hampers Cell Growth, Migration, and Stem Cell Properties in Bladder Cancer through Sponging miR-641 to Upregulate PTEN. Cell Cycle 20, 1589-1602. doi:10.1080/15384101.2021.1954758

Vicens, Q., and Westhof, E. (2014). Biogenesis of Circular RNAs. Cell 159 (1), 13-14. doi:10.1016/j.cell.2014.09.005

Vitiello, M., Evangelista, M., Zhang, Y., Salmena, L., Pandolfi, P. P., and Poliseno, L. (2020). PTENP1 Is a ceRNA for PTEN: It's CRISPR clear. J. Hematol. Oncol. 13 (1), 73. doi:10.1186/s13045-020-00894-2

Vo, J. N., Cieslik, M., Zhang, Y., Shukla, S., Xiao, L., Zhang, Y., et al. (2019). The Landscape of Circular RNA in Cancer. Cell 176 (4), 869-881.e813. doi:10.1016/ j.cell.2018.12.021

Wang, K., Sun, Y., Tao, W., Fei, X., and Chang, C. (2017a). Androgen Receptor (AR) Promotes clear Cell Renal Cell Carcinoma (ccRCC) Migration and Invasion via Altering the circHIAT1/miR-195-5p/29a-3p/29c-3p/CDC42 Signals. Cancer Lett. 394, 1-12. doi:10.1016/j.canlet.2016.12.036

Wang, S., Wang, X., Li, J., Meng, S., Liang, Z., Xu, X., et al. (2017b). c-Met, CREB1 and EGFR Are Involved in miR-493-5p Inhibition of EMT via AKT/GSK-3 $\beta /$ Snail Signaling in Prostate Cancer. Oncotarget 8 (47), 82303-82313. doi:10.18632/oncotarget.19398

Wang, S., Zhang, K., Tan, S., Xin, J., Yuan, Q., Xu, H., et al. (2021a). Circular RNAs in Body Fluids as Cancer Biomarkers: the New Frontier of Liquid Biopsies. Mol. Cancer 20 (1), 13. doi:10.1186/s12943-020-01298-z

Wang, X., Wang, R., Wu, Z., and Bai, P. (2019). Circular RNA ITCH Suppressed Prostate Cancer Progression by Increasing HOXB13 Expression via Spongy miR-17-5p. Cancer Cel Int 19, 328. doi:10.1186/s12935-019-0994-8

Wang, X., Xing, L., Yang, R., Chen, H., Wang, M., Jiang, R., et al. (2021b). The circACTN4 Interacts with FUBP1 to Promote Tumorigenesis and Progression of Breast Cancer by Regulating the Expression of Proto-Oncogene MYC. Mol. Cancer 20 (1), 91. doi:10.1186/s12943-021-01383-x

Wilusz, J. E. (2019). Circle the Wagons: Circular RNAs Control Innate Immunity. Cell 177 (4), 797-799. doi:10.1016/j.cell.2019.04.020

Wilusz, J. E., and Sharp, P. A. (2013). A Circuitous Route to Noncoding RNA. Science 340 (6131), 440-441. doi:10.1126/science. 1238522

Wu, G., Sun, Y., Xiang, Z., Wang, K., Liu, B., Xiao, G., et al. (2019). Preclinical Study Using Circular RNA 17 and Micro RNA 181c-5p to Suppress the EnzalutamideResistant Prostate Cancer Progression. Cel Death Dis 10 (2), 37. doi:10.1038/ s41419-018-1048-1

Wu, W., Ji, P., and Zhao, F. (2020). CircAtlas: an Integrated Resource of One Million Highly Accurate Circular RNAs from 1070 Vertebrate Transcriptomes. Genome Biol. 21 (1), 101. doi:10.1186/s13059-020-02018-y

Wu, X., Xiao, S., Zhang, M., Yang, L., Zhong, J., Li, B., et al. (2021). A Novel Protein Encoded by Circular SMO RNA Is Essential for Hedgehog Signaling Activation and Glioblastoma Tumorigenicity. Genome Biol. 22 (1), 33. doi:10.1186/ s13059-020-02250-6

Xie, F., Li, Y., Wang, M., Huang, C., Tao, D., Zheng, F., et al. (2018). Circular RNA BCRC-3 Suppresses Bladder Cancer Proliferation through miR-182-5p/p27 axis. Mol. Cancer 17 (1), 144. doi:10.1186/s12943-018-0892-z

Xiong, Y., Zhang, J., and Song, C. (2019). CircRNA ZNF609 Functions as a Competitive Endogenous RNA to Regulate FOXP4 Expression by Sponging miR-138-5p in Renal Carcinoma. J. Cel Physiol 234 (7), 10646-10654. doi: $10.1002 /$ jcp. 27744

Xu, H., Jiang, Y., Xu, X., Su, X., Liu, Y., Ma, Y., et al. (2019). Inducible Degradation of IncRNA Sros1 Promotes IFN- $\gamma$-Mediated Activation of Innate Immune Responses by Stabilizing Stat1 mRNA. Nat. Immunol. 20 (12), 1621-1630. doi:10.1038/s41590-019-0542-7

Xu, H., Sun, Y., You, B., Huang, C.-P., Ye, D., and Chang, C. (2020). Androgen Receptor Reverses the Oncometabolite R-2-Hydroxyglutarate-Induced Prostate Cancer Cell Invasion via Suppressing the circRNA-51217/miRNA-646/TGF $\beta 1$ / p-Smad2/3 Signaling. Cancer Lett. 472, 151-164. doi:10.1016/ j.canlet.2019.12.014 
Xue, D., Wang, H., Chen, Y., Shen, D., Lu, J., Wang, M., et al. (2019). Circ-AKT3 Inhibits clear Cell Renal Cell Carcinoma Metastasis via Altering miR-296-3p/ E-Cadherin Signals. Mol. Cancer 18 (1), 151. doi:10.1186/s12943-019-1072-5

Yang, C., Wu, S., Wu, X., Zhou, X., Jin, S., and Jiang, H. (2019a). Silencing Circular RNA UVRAG Inhibits Bladder Cancer Growth and Metastasis by Targeting the microRNA-223/fibroblast Growth Factor Receptor 2 axis. Cancer Sci. 110 (1), 99-106. doi:10.1111/cas.13857

Yang, C., Yuan, W., Yang, X., Li, P., Wang, J., Han, J., et al. (2018). Circular RNA Circ-ITCH Inhibits Bladder Cancer Progression by Sponging miR-17/miR-224 and Regulating P21, PTEN Expression. Mol. Cancer 17 (1), 19. doi:10.1186/ s12943-018-0771-7

Yang, J., Antin, P., Berx, G., Blanpain, C., Brabletz, T., Bronner, M., et al. (2020). Guidelines and Definitions for Research on Epithelial-Mesenchymal Transition. Nat. Rev. Mol. Cel Biol 21 (6), 341-352. doi:10.1038/s41580-020-0237-9

Yang, Z., Qu, C.-B., Zhang, Y., Zhang, W.-F., Wang, D.-D., Gao, C.-C., et al. (2019b). Dysregulation of P53-RBM25-Mediated circAMOTL1L Biogenesis Contributes to Prostate Cancer Progression through the circAMOTL1L-miR-193a-5p-Pcdha Pathway. Oncogene 38 (14), 2516-2532. doi:10.1038/s41388-018-0602-8

Zang, R., Qiu, X., Song, Y., and Wang, Y. (2021). Exosomes Mediated Transfer of Circ_0000337 Contributes to Cisplatin (CDDP) Resistance of Esophageal Cancer by Regulating JAK2 via miR-377-3p. Front. Cel Dev. Biol. 9, 673237. doi:10.3389/fcell.2021.673237

Zhang, D., Yang, X.-J., Luo, Q.-D., Fu, D.-L., Li, Z.-L., Zhang, P., et al. (2019a). Down-Regulation of Circular RNA_000926 Attenuates Renal Cell Carcinoma Progression through miRNA-411-dependent CDH2 Inhibition. Am. J. Pathol. 189 (12), 2469-2486. doi:10.1016/j.ajpath.2019.06.016

Zhang, S., Zhang, X., Chen, G., Zheng, X., Zhu, X., and Shan, L. (2020). Hsa_circ_0007494 Suppresses Prostate Cancer Progression via miR-616/ PTEN axis. Exp. Cel. Res. 395 (2), 112233. doi:10.1016/j.yexcr.2020.112233

Zhang, W.-Y., Liu, Q.-H., Wang, T.-J., Zhao, J., Cheng, X.-H., and Wang, J.-S. (2019b). CircZFR Serves as a Prognostic Marker to Promote Bladder Cancer Progression by Regulating miR-377/ZEB2 Signaling. Biosci. Rep. 39 (12). doi:10.1042/bsr20192779

Zhang, X.-O., Dong, R., Zhang, Y., Zhang, J.-L., Luo, Z., Zhang, J., et al. (2016). Diverse Alternative Back-Splicing and Alternative Splicing Landscape of Circular RNAs. Genome Res. 26 (9), 1277-1287. doi:10.1101/gr.202895.115

Zhang, X.-O., Wang, H.-B., Zhang, Y., Lu, X., Chen, L.-L., and Yang, L. (2014). Complementary Sequence-Mediated Exon Circularization. Cell 159 (1), 134-147. doi:10.1016/j.cell.2014.09.001

Zhang, Y., Kwok-Shing Ng, P., Kucherlapati, M., Chen, F., Liu, Y., Tsang, Y. H., et al. (2017). A Pan-Cancer Proteogenomic Atlas of PI3K/AKT/mTOR Pathway Alterations. Cancer cell 31 (6), 820-832.e823. doi:10.1016/j.ccell.2017.04.013

Zhang, Y., Liu, Y., Liu, H., and Tang, W. H. (2019c). Exosomes: Biogenesis, Biologic Function and Clinical Potential. Cell Biosci 9, 19. doi:10.1186/s13578-019-0282-2
Zhang, Y., Zhang, X.-O., Chen, T., Xiang, J.-F., Yin, Q.-F., Xing, Y.-H., et al. (2013). Circular Intronic Long Noncoding RNAs. Mol. Cel. 51 (6), 792-806. doi:10.1016/j.molcel.2013.08.017

Zhao, Q., Liu, J., Deng, H., Ma, R., Liao, J.-Y., Liang, H., et al. (2020a). Targeting Mitochondria-Located circRNA SCAR Alleviates NASH via Reducing mROS Output. Cell 183 (1), 76-93.e22. doi:10.1016/j.cell.2020.08.009

Zhao, Y., Zheng, R., Chen, J., and Ning, D. (2020b). CircRNA CDR1as/miR-641/ HOXA9 Pathway Regulated Stemness Contributes to Cisplatin Resistance in Non-small Cell Lung Cancer (NSCLC). Cancer Cel Int 20, 289. doi:10.1186/ s12935-020-01390-w

Zheng, F., Wang, M., Li, Y., Huang, C., Tao, D., Xie, F., et al. (2019). CircNR3C1 Inhibits Proliferation of Bladder Cancer Cells by Sponging miR-27a-3p and Downregulating Cyclin D1 Expression. Cancer Lett. 460, 139-151. doi:10.1016/ j.canlet.2019.06.018

Zhong, Z., Huang, M., Lv, M., He, Y., Duan, C., Zhang, L., et al. (2017). Circular RNA MYLK as a Competing Endogenous RNA Promotes Bladder Cancer Progression through Modulating VEGFA/VEGFR2 Signaling Pathway. Cancer Lett. 403, 305-317. doi:10.1016/j.canlet.2017.06.027

Zhou, B., Zheng, P., Li, Z., Li, H., Wang, X., Shi, Z., et al. (2018). CircPCNXL2 Sponges miR-153 to Promote the Proliferation and Invasion of Renal Cancer Cells through Upregulating ZEB2. Cell Cycle 17 (23), 2644-2654. doi:10.1080/ 15384101.2018.1553354

Zhu, H., Wang, S., Shen, H., Zheng, X., and Xu, X. (2020). SP1/AKT/FOXO3 Signaling Is Involved in miR-362-3p-Mediated Inhibition of Cell-Cycle Pathway and EMT Progression in Renal Cell Carcinoma. Front. Cel Dev. Biol. 8, 297. doi:10.3389/fcell.2020.00297

Conflict of Interest: The authors declare that the research was conducted in the absence of any commercial or financial relationships that could be construed as a potential conflict of interest.

Publisher's Note: All claims expressed in this article are solely those of the authors and do not necessarily represent those of their affiliated organizations or those of the publisher, the editors, and the reviewers. Any product that may be evaluated in this article, or claim that may be made by its manufacturer, is not guaranteed or endorsed by the publisher.

Copyright (c) 2021 Wang, Ying, Ma, Wang, Wang and Xie. This is an open-access article distributed under the terms of the Creative Commons Attribution License (CC $B Y)$. The use, distribution or reproduction in other forums is permitted, provided the original author(s) and the copyright owner(s) are credited and that the original publication in this journal is cited, in accordance with accepted academic practice. No use, distribution or reproduction is permitted which does not comply with these terms. 